\title{
OUTCOME OF BARIUM ENEMA IN PATIENTS WITH COLORECTAL SYMPTOMS
}

\author{
Y. B. MENSAH, J.C.B. DAKUBO, S. ASIAMAH and S. B. NAAEDER ${ }^{2}$ \\ Departments of Radiology and Surgery, Korle Bu Teaching Hospital, P.O. Box KB 77 Korle Bu, Accra, \\ Ghana, ${ }^{2}$ Department of Surgery, University of Ghana Medical School, P.O. Box 4326, Accra. Ghana
}

\author{
Author for correspondence: $\operatorname{Dr} Y$. B. Mensah \\ Conflict of Interest: None declared
}

\section{SUMMARY}

Background: For many years, double contrast barium enema has been an effective way to evaluate the large bowel. With the development of the colonoscope, the role of barium enema has been questioned. However it is still useful in investigating patients with colorectal symptoms especially in the developing world where colonoscopy is widely unavailable and fraught with challenges in completely evaluating the colon.

Objective: This study aimed at reviewing double contrast barium enema investigations in our centre.

Methods: This was a retrospective study on patients who underwent double contrast barium enema at the Korle $\mathrm{Bu}$ Teaching Hospital from May 2003 to April 2007 on account of symptoms referable to the large bowel.

Results: A total of 362 investigation reports were studied, of which 205 were for males and 154 for females, the mean age of the patients was 55.3 years (S.D 15.3years). Majority of the investigations, 228 (61.96\%), were normal. Diverticular disease diagnosed in $88(23.91 \%)$ cases was the commonest finding, followed by neoplasm $27(7.34 \%)$ cases and Ulcerative colitis $6(1.63 \%)$ cases, non-specific narrowing of the bowel in $4(1.09 \%)$ and in $5(1.36 \%)$ cases their investigations were inconclusive due to poor bowel preparation. Rectal bleeding was the most frequent symptom prompting barium enema studies.

Conclusion: Double contrast barium enema study of the large bowel is an important evaluation of patients with colorectal symptoms. .

Keywords: Barium enema, Colonoscopy, Rectal bleeding, Diverticular disease, Colorectal carcinoma.

\section{INTRODUCTION}

For many years, barium enema was the only way to obtain a complete structural examination of the colon, short of surgery. Development of the double-contrast barium enema improved the ability of the method to detect subtle lesions by making it appropriate for detecting polyps and potentially curable cancers. With the advent of fiberoptic technology and the widespread use of colonoscopy in the 1970s, the role of barium enema has been questioned. ${ }^{1,2}$ Colonoscopy is currently the ideal investigative tool for the colon since it combines detection of lesions with biopsy and/or treatment. This notwithstanding, the role of double contrast barium enema in investigating patients with colorectal symptoms cannot be denigrated since it still has a permissive role in diagnosis. This is so when viewed against the background that in reported large series in general practice colonoscopy was infrequently employed to investigate the large bowel ${ }^{3}$. It has been shown in our centre that only $30 \%$ of patients presenting with rectal bleeding had colonoscopy of which complete examination was achieved in $30 \%$; the rest having to complete their investigation with the double contrast barium enema. ${ }^{4}$ Median colonoscopy completion rates found in an audit in three regions in the United Kingdom were between $57 \%$ and $73 \%{ }^{5}$. A snapshot on colonoscopy practice in 68 English units reported caecal intubation rates of $77 \%$, falling to $57 \%$ when the strict criteria of appendiceal orifice identification or intubation of the ileocaecal valve were used ${ }^{6}$. The limited success in complete colonoscopy has been attributed to inexperience, poor bowel preparation and patient discomfort. Obstructing lesions and redundant loops of large bowel, frequently noted in the African, which are difficult to negotiate even in experienced hands were and may remain important insurmountable causes of failure of colonoscopy in this part of the world. The unflinching role of double contrast barium enema is further demonstrated in the role assigned to it in screening for colorectal carcinoma in the US guidelines for colorectal cancer screening. ${ }^{7,8}$

With the modest improvement in socio-economic performance attended with increasing urbanization that has accordingly modified dietary habits, and coupled with the progressive increase in the aged population resulting from the increase in life expectancy and the rapid decline in fertility in Ghana ${ }^{9}$, colorectal diseases that were formally uncommon have begun to assume prominence. ${ }^{10}$ To provide a guide to help in formulating local policy for early diagnosis of colorectal diseases it is imperative to re-emphasize the role that double contrast barium enema plays in the investigation of 
patients with colorectal symptoms in our centre. This three-year retrospective study was aimed at defining the patient's characteristics, the symptoms that necessitated the test, the success achieved, and the diagnostic yield in patients who underwent barium enema investigation.

\section{PATIENTS AND METHODS}

This was a retrospective study conducted on patients who underwent double contrast barium enema at the Korle Bu Teaching Hospital from May 2003 to April 2007 on account of symptoms referable to the large bowel. Data was collected from both Radiological Request forms and the Duplicates of final reports written for the procedure. In some cases the duplicates were the only source of data. Information gathered included age, sex, indication for the investigation and radiological findings.

\section{RESULTS}

A total of 362 investigation reports were studied, of which 205 were for males and 154 for females giving a ratio of $1.3: 1$. The mean age of the patients was 55.3 years (S.D 15.3years); that for males was 54.4 years (S.D 12.7years) and that for females was 56.5 years (S.D 14.3 years). The ages of 29 (8\%) cases investigated were not recorded.

Table 1 General findings

\begin{tabular}{|l|l|l|}
\hline Finding & $\begin{array}{l}\text { No. of } \\
\text { Patients }\end{array}$ & \% \\
\hline Normal & 228 & 62.0 \\
\hline Diverticular disease & 88 & 23.9 \\
\hline Neoplasia & 27 & 7.3 \\
\hline Ulcerative colitis & 6 & 1.6 \\
\hline $\begin{array}{l}\text { Nonspecific narrowing of } \\
\text { bowel }\end{array}$ & 4 & 1.1 \\
\hline $\begin{array}{l}\text { Nonspecific findings need- } \\
\text { ing further evaluation }\end{array}$ & 4 & 1.1 \\
\hline $\begin{array}{l}\text { Fistulae(2 between small } \\
\text { and large bowel; one en- } \\
\text { terocutaneous) }\end{array}$ & 3 & 0.8 \\
\hline Nonspecific Colitis & 2 & 0.5 \\
\hline Posterior rectal ulcer & 1 & 0.3 \\
\hline $\begin{array}{l}\text { Inconclusive, due to poor } \\
\text { bowel preparation }\end{array}$ & 5 & 1.4 \\
\hline Total & 368 & 100 \\
\hline
\end{tabular}

Majority of the investigations, 228 (61.96\%), were normal (Table 1). Diverticular disease diagnosed in 88 $(23.91 \%)$ cases was the commonest finding, followed distantly by neoplasm $27(7.34 \%)$ cases, Ulcerative colitis $6(1.63 \%)$ cases, nonspecific narrowing of the bowel in $4(1.09 \%)$ and in $5(1.36 \%)$ cases their inves- tigations were inconclusive due to poor bowel preparation.

Table 2 depicts the symptoms, either singly or in combination, that were presented by patients investigated with barium enema. Rectal bleeding was the most frequent symptom prompting barium enema studies. Abdominal pain/discomfort, constipation, change in bowel habits and abdominal masses were the next frequent symptoms, in decreasing order of frequency, noted among the patients.

Table 2: Reasons for ordering barium enema

\begin{tabular}{|l|l|l|}
\hline \multicolumn{1}{|c|}{ Indication } & $\begin{array}{c}\text { No. of } \\
\text { Patients }\end{array}$ & \% \\
\hline Bleeding pr & 102 & 25.1 \\
\hline Abdominal pain/ discomfort & 73 & 17.9 \\
\hline Change in bowel habits & 58 & 14.3 \\
\hline Constipation & 51 & 12.5 \\
\hline Abdominal Mass & 23 & 5.7 \\
\hline Diarrhoea & 10 & 2.5 \\
\hline Abdominal distension & 9 & 2.2 \\
\hline Weight loss & 7 & 1.7 \\
\hline Tenesmus & 6 & 1.5 \\
\hline Mucus Discharge Per Rectum & 4 & 1.0 \\
\hline $\begin{array}{l}\text { Haemorrhoids, to screen bowel } \\
\text { for other pathologies }\end{array}$ & 4 & 1.0 \\
\hline Rectal Prolapse & 3 & 0.7 \\
\hline Fistula( in ano, enterocutaneous) & 3 & 0.7 \\
\hline Bloody mucoid discharge & 2 & 0.5 \\
\hline Rectal Polyp & 2 & 0.5 \\
\hline $\begin{array}{l}\text { Recurrent appendicitis. To } \\
\text { screen bowel for other large } \\
\text { bowel pathologies }\end{array}$ & & \\
\hline Resolved Volvulus & 1 & 0.2 \\
\hline $\begin{array}{l}\text { Epigastric tenderness, increased } \\
\text { flatulence }\end{array}$ & 1 & 0.2 \\
\hline $\begin{array}{l}\text { Pyoderma gangrenosum, to rule } \\
\text { out inflammatory bowel disease }\end{array}$ & 1 & 0.2 \\
\hline Rectal pain & 1 & 0.2 \\
\hline To test the repair of rectal injury & 1 & 0.2 \\
\hline bloating & 1 & 0.2 \\
\hline $\begin{array}{l}\text { Symptoms not directly related to } \\
\text { large bowel }\end{array}$ & 3 & 0.7 \\
\hline Not stated & 41 & 10.1 \\
\hline Total & 407 & 100 \\
\hline
\end{tabular}

Diverticular disease $42(41.18 \%)$ cases, neoplasia 10 $(9.8 \%)$ cases and ulcerative colitis $2(1.96 \%)$ cases, as indicated in Table 3, accounted for most of the pathological findings in patients investigated for rectal bleeding. As many as $44(43.14 \%)$ cases with rectal bleeding had normal barium enema finding. 
Table 3: Findings in patients who presented with bleeding per rectum

\begin{tabular}{|l|l|l|}
\hline Findings & $\begin{array}{l}\text { No of } \\
\text { Patients }\end{array}$ & \% \\
\hline Normal & 44 & 43.1 \\
\hline Diverticular disease & 42 & 41.2 \\
\hline Neoplasia & 10 & 9.8 \\
\hline Ulcerative colitis & 2 & 2.0 \\
\hline $\begin{array}{l}\text { Nonspecific findings needing } \\
\text { further evaluation }\end{array}$ & 2 & 2.0 \\
\hline $\begin{array}{l}\text { Inconclusive, poor bowel prepa- } \\
\text { ration }\end{array}$ & 2 & 2.0 \\
\hline Total & 102 & 100 \\
\hline
\end{tabular}

Of the 88 cases of diverticular disease diagnosed 44 were males and 43 females (ratio M:F, 1:1). About $80 \%$ of the patients with diverticular disease were aged between 51 and 80 years.

Solitary diverticulum was found in 16 patients while multiple diverticular were found in 72 patients. The distribution of the diverticular lesions in the various segments of the large bowel show that a single segment was involved in $41(46.59 \%)$ cases, two segment involvement in $23(26.14 \%)$ cases and more that two segment involvement in $24(27.27 \%)$ cases.

Patients with diverticular disease presented with many symptoms that were related to large bowel disease. Rectal bleeding 42 (47.19\%) patients, change in bowel habits $12(13.48 \%)$ patients, abdominal pain $8(8.99 \%)$ and constipation $5(5.62 \%)$ were the most frequent symptoms.

Neoplastic lesions were identified in 27 patients out of which 22 had radiological features suggestive of malignancy while 5 were polyps. There were more males than females (ratio, M:F 1.4:1) with neoplastic lesions. Malignant lesions were most frequent, $45.45 \%$, in age group 51-60 years. Malignant lesions were frequently noticed in the transverse colon $6(27.2 \%)$ followed by the caecum and rectum $4(18.18 \%)$ in each.

\section{DISCUSSION}

Double contrast barium enema is a radiological investigation of the colon done by introducing barium sulphate and air into the colon through the rectum. It provides a panoramic view of the whole colon and has the ability to precisely localize and determine the extent of colonic lesions. ${ }^{11}$

To evaluate the whole of the colon, barium enema is a feasible diagnostic tool which is easily executed, causes the patient only minor discomfort and with a high rate of complete examination. ${ }^{11}$ It is rated high in terms of safety, convenience, acceptance by patients, cost, and cost effectiveness, as well as on the number of physicians needed to conduct the examination properly. ${ }^{1}$ This examination also provides a film dossier that is portable, accessible to different radiologists and always available for comparison without necessarily having to bring the patient back. ${ }^{11}$ With adequate training and the requisite logistics, the investigation can be performed in health institutions outside the tertiary centres where it is currently largely based in Ghana.

In this study we found a very high number of the investigations to be normal $228(61.96 \%)$. This may be because, for a large number of the patients, their requests were intended for screening the colon for other conditions with similar clinical features. In addition people aged 50 years and above have an average risk for developing colorectal cancer; majority of the people studied were in this age group and this may also have been a guide for some of the requests. The high normal rate could also be due to the fact that barium enema does not fare too well as the sole screening examination since it does not examine the distal rectum and anus thus making digital rectal examination and proctoscopy mandatory in such situations. ${ }^{1}$

The non-specific narrowing of the bowel seen in 4 cases could be due to malignant infiltration of the colon, post amoebic stricture or inflammatory bowel disease. It may also be a feature of the prediverticular stage of diverticular disease which is usually characterized by narrowing of the lumen, thickening of the wall of the colon and crowding of haustra markings(saw tooth appearance). ${ }^{12,13}$ Endoscopic evaluation of these patients will be insightful.

Ulcerative colitis has for long been thought to be a disease of the West. ${ }^{12}$ However being the third commonest finding with an approximate prevalence of $2 \%$ in this study, is an indication that it is not rare in our environment.

The commonest finding was diverticular disease portraying the high sensitivity of barium enema in diagnosing this disease which can easily be missed at colonoscopy. ${ }^{13}$ There was a male to female ratio of $1: 1$ which compares with other studies. ${ }^{12,13}$ Diverticular disease in this study was found to be uncommon before 50 years constituting only $6.82 \%$ of the total number of patients with the disease and corroborates earlier reports from Accra. ${ }^{14,15}$

The age group with the highest incidence of diverticular disease was the 61-70 year group which was followed closely by 71-80 year group confirming that it is 
a disease of the aged and has a high incidence after the $7^{\text {th }}$ decade. $^{12,13,14}$

Majority of the diverticuli were multiple and involved more than two segments of the bowel. ${ }^{15}$ Contrary to reports from other centres where $85 \%$ of diverticuli were in the left colon, in this study $43.19 \%$ were on the right compared with $26.15 \%$ on the left; ${ }^{13}$ a distribution pattern described by earlier studies from this centre. ${ }^{14}$, ${ }_{15}$ Right sided diverticuli are believed to take a more benign cause than those on the left. ${ }^{13}$

Many people with diverticuli are usually asymptomatic and are usually found incidentally. Bleeding, fistula formation and infection (diverticulitis) are the usual complications of diverticular disease which give patients the symptoms that lead them to seek medical help. In our study the commonest symptom associated with diverticular disease was bleeding. This correlates with findings in other studies where diverticular disease is believed to be the commonest cause of lower gastrointestinal bleeding. ${ }^{12,14,15,16}$

Computed tomography is usually the preferred diagnostic tool when complicated diverticular disease is suspected. This is especially so in diverticulitis when barium enema is contraindicated. ${ }^{12} 13$ This is however limited by cost and availability in the developing world. Diverticulitis is however rare in Africans with diverticuli. $^{14}$

Neoplastic lesions were the second commonest finding accounting for $7.34 \%$ of the diagnoses. The yield for polyps was low, $1.34 \%$. This situation is worrying if premalignant lesions are to be diagnosed and treated early to prevent malignant transformation. Many studies have demonstrated that barium enema has a low sensitivity in the detection of early polyps, when they are small $(<0.5 \mathrm{~cm})$. The sensitivity of barium enema in the detection of polyps is related to polyp size. This investigative tool is therefore not adequate for screening for premalignant colorectal lesions and has to be complemented with endoscopy. ${ }^{11}$

\section{CONCLUSION}

Double contrast barium enema study of the large bowel is an important evaluation of patients with colorectal symptoms. It has a high yield in the diagnosis of important colorectal conditions like diverticular disease and malignant lesions.

\section{REFERENCES}

1. Fletcher R H. The End of Barium Enemas? $N$. Engl. J. Med 2000. Jun; 342(24): 18231824(Editorial)
2. A Comparison of Colonoscopy and Double Contrast Barium Enema for Surveillance after polypectomy. National Polyps Study Work Group. $N$. Engl. J. Med 342:1766,2000.

3. Vernawa A. M, Longo W. E, Virgo K. S. A Nationwide study of Incidence and Etiology of Lower Gastrointestinal bleeding. Surg. Res. Commun. 1996; 18:113-120.

4. Dakubo J. C. B, Kumodji R, Naaeder S. B, CleggLamptey J. N. Endoscopic evaluation of the colorectum in patients presenting with haematochezia at Korle $\mathrm{Bu}$ Teaching Hospital. Accra. Ghana Medical J 2008; 42(1):

5. Bowles C. J. A, Leicester R, Romanya C, Swarbrick E, Williams C B, Epstein O. A. Prospective study of Colonoscopy practice in the UK today: are we adequately prepared for National Colorectal Cancer screening tomorrow? Gut 2004; 53: 277 283.

6. Palmer K, Marris A. T. A Snapshort of colonoscopy Practice in England: Stimulus for Improvement. Gut 2004; 53: 163 -165(commentary)

7. Screening for Colorectal Cancer: Recommendation and Rationale. U. S preventive services Task force. Ann Inter Med 137: 129, 2002.

8. American Cancer Society guidelines for early detection of cancer, 2003, American Cancer Society: C A Cancer .Clin. 53:27, 2003.

9. Ghana Statistical Service (GSS). 2002a, 2000 Population and Housing Census; Summary Report of final Results. The GSS, Accra.

10. Biritwum R B, Gulaid J, Amaning A. O. Pattern of Diseases or conditions leading to hospitalization at Korle Bu Teaching Hospital, Ghana in 1996. Ghana Med J. 2000; 34(4): 197 -205

11. Bellomi M, Spagnoli I, Zucchi F. Digestive System and Biliary Tract. In: Damascelli B.(Editor) Basic Concepts in Diagnostic Imaging. Ravern Press. 1991 pp 29- 50.

12. Dähnert W. Gastrointestinal Tract. In: Radiology Review Manual ( $5^{\text {th }}$ Edition). Lippincott Williams \& Wilkins. 2002 pp $743-866$.

13. Ferzoco L. B., Raptopoulos V., Silen W. Acute Diverticulitis. N. Engl J. Med 1998. May; 338(21): 1521- 1526.

14. Baako B. Diverticular disease of the colon in Accra, Ghana. Br J Surg. 2001;88:1595.

15. Archampong EQ, Christian F, Badoe E A. Diverticular disease in an indigenous African community. Ann R Coll. Surg. Engl. 1978;60:464-70

16. Jensen D. M., Machicado G. A., Jutabha R., Kovacs T. O. G. Urgent Colonoscopy for the Diagnosis and Treatment of Severe Diverticular Hemorrhage. N. Engl. J Med. 2000. Jan; 342(2): 78- 82. 